International Journal of Biology, Pharmacy and Allied Seiences (IJBPAS) 'A Bridge Betusen Caboratory and Q Qundo'

WwW.ijbpas.com

\title{
FORMULATION AND EVALUATION OF NANOPARTICLES USING CHITOSAN AS POLYMERS AND OCIMUM TENUIFLORUM LEAF AND ZINGIBER OFFICINALE STEM EXTRACTS
}

\section{KUMAR A* AND GUPTA G}

School of Pharmacy, Monad University, Hapur, U.P., India

*Corresponding Author: Anil Kumar: E Mail: akyadavf5@gmail.com; Contact No: +919415512288

Received $19^{\text {th }}$ Aug. 2020; Revised $18^{\text {th }}$ Sept. 2020; Accepted $9^{\text {th }}$ Oct. 2020; Available online $1^{\text {st }}$ July 2021 https://doi.org/10.31032/IJBPAS/2021/10.7.5545

\begin{abstract}
Aim and objective: The aim of the present study was to develop the nanoparticles consisting etoricoxib with ethanolic extract of ginger (Zingiber officinale, Zingiberaceae) root and tulsi (Ocimum sanctum L, Lamiaceae) leaves prepared nanoparticles using Chitosan as polymers treatment of diabetes complications.

Material and method: Nanoparticles were prepared by the antisolvent method by using a different concentration of polymer (Chitosan) and extract while concentration of etoricoxib was remain constant in all the formulations. The prepared nanoparticle was evaluated for different parameters.
\end{abstract}

Result \& discussion: The formulation of nanoparticles was evaluated for various parameters such as viscosity, washability, consistency, $\mathrm{pH}$, spreadability and in-virro drug release study. The constancy of the formulations size of pores was found ranging from $924 \mathrm{~nm}$ was observed. The $\mathrm{pH}$ of the nanoparticles was found to be $6.1 \pm 0.009$ (F2) to $6.1 \pm 0.098$ (F7) whereas the viscosity was found in the range of $0.901 \pm 0.010$ (F7) to $1.200 \pm 0.055 \mathrm{micm} 3$ (F9). The Spreadability was found in the range of $61.9 \pm 0.025 \%$ (F5) to $71.01 \pm 0.016 \%$ (F4). The drug content of etoricoxib in the formulations was found in the range of $63.9 \pm 0.11$ (F8) to $77.5 \pm 0.06$ (F9). GE $58.9 \pm 0.01$ 
(F7) to $62.9 \pm 0.05$ (F1) and BE 35.9 \pm 0.01 (F3) to $64.9 \pm 0.05$ (F9). The drug release was taken up to $24 \mathrm{~h}$ and found to be $99 \%$ for all the formulations.

Conclusion: The results showed that the nanoparticles were prepared successfully.

\section{Keywords: Nanoparticles, Chitosan Polymers, Ocimum Tenuiflorum, Zingiber Officinale INTRODUCTION}

Nanoparticles contain particular characteristics such the same as the smaller size of particles, a specific shape, and particle size distribution. They have a larger surface area than macro particles because of their small size $(1-100 \mathrm{~nm})$ the term is sometime used for larger particles $\mathrm{p}$ to $500 \mathrm{~nm}$. [1]. According the equation of Noyes-Whitney the interfacial surface area is increased by reducing the particle size in the nano range therefore the solubility and rate of dissolution is poorly water-soluble drugs can be improved [2]. They contain potential to improve the therapeutic effects of drugs from side to side increasing the efficacy of the drug, lesser toxic effects of the drug, and attain the steady-state therapeutic level and also humanizing the solubility and drug stability [3]. The increase in the dissolution rate of the poorly water-soluble drug is essential to optimize the bioavailability [4].

Etoricoxib is a potent compound of COX-2 inhibitors. It inhibits the isoform-2 of the enzyme cox-2 and generates the prostaglandins from arachidonic acid. It is a BCS class II drug and used as an antiinflammatory agent in the treatment of many diseases [1]. When Etoricoxib administered orally, it shows severe side effects and low dissolution rate [5]. To avoid these problems, it requires solubility enhancement and sitespecific drug delivery. So the site-specific topical carriers improve the efficiency of the drug through sustained release [1].

The antisolvent precipitation method is used to prepare the nano and micro particles. It is a bottom-up method which provides suitable procedures at a maintained temperature [6]. Under the sonication process, it is a rapid and low-cost method. The antisolvent solution is prepared by the polymer, surfactant and the mixture of both as a stabilizing agent then the solution of drug in an organic solvent is prepared and added to the antisolvent. This is important to maintain the conditions such as the rapid formation of particles and no growth of particle size for the preparation of nanoparticles [7]. The precipitation of nanoparticles is achieved by various steps such as mixing of solution and antisolvent, supersaturation, nucleation, and growth through condensation. Rapid and 
supersaturation precipitation occurs through the main driving force. During the crystallization process, supersaturation generated and properties of crystal such as size, shape, purity depend on the uniformity and rate of supersaturation [6]. Nile et al studied the various effects of ginger (Zingiber officinale, Zingiberaceae) extract such as anti-inflammatory, antioxidant, and xanthine oxidase inhibitory activities. They determined the anti-inflammatory activity of ginger extract through diene conjugate, 13glucuronidase inhibition, hyaluronidase inhibition and lipoxidase inhibition assay in vitro. They found that the 6-gingerol, 8gingerol, 10-gingerol, 6-shadow, and 6paradol are the active constituents of ginger which have various properties such as antioxidant, anti-inflammatory, anticancer activities [8]. Zlotek et al found that the basil leaves contains various properties such as anti-inflammatory, antioxidant, and anticancer activity [9]. Chitra et al developed the nanoparticles of the ginger extract by using poloxamer 188 as stabilizing agent through green synthesis and found that the zinger extract with poloxamer 188 incorporated gold nanoparticles is more effective than pure zinger extract [10]. In the present investigation, etoricoxib nanoparticles were prepared by an antisolvent method by using Chitosan as polymers polysaccharide and phytoconstituents such as ethanolic extract of ginger root and tulsi leaves. Then the prepared nanoparticles were incorporated into the gel for enhancing the solubility of drug. The prepared nanoparticles incorporated gel was applied locally for targeting the skin to reduce the pain and inflammation associated with human skin melanoma cancer. The extract used in formulation contains antioxidant properties and potentiate the action of drug etoricoxib.

\section{MATERIALS AND METHOD}

\section{Materials:}

Ginger (Zinger Zingiber officinale, Zingiberaceae) root, tulsi (Ocimum sanctum $L$, Lamiaceae) leaves were collected from a local area of omicron 1A Greater Noida U.P.

\section{Method:}

\section{Preparation of ginger rhizome and tulsi} leaves extract:

Fresh plant leaves of Ocimum sanctum $L$. were collected from a local area of omicron 1A Greater Noida U.P. (28 $38^{\circ} \mathrm{N}, 77^{\circ} 12^{\prime}$ E). The leaves were washed thoroughly under tap water followed by sterile distilled water. Then leaves were dried under shaded condition at room temperature. Sampling of Ocimum sanctum L. was planted in the month of March. Middle aged fresh leaves of 
Ocimum sanctum L. were plucked during the month of September- October in the morning between 9-10 a.m. (IST) when dew was less and temperature was also not so high and fresh ginger stem (Zingiber officinale) were procured from local market. The stem were washed with distilled water and dried in oven at $40{ }^{\circ} \mathrm{C}$, about 5 to $10 \mathrm{~min}$.

\section{Extraction of plant material:}

Dry ginger was crushed to a coarse powder and extracted with $95 \%$ ethanol by simple maceration process. Solvent was evaporated at room temperature. The residue obtained was dried. As well as the dried leaves material (in $20 \mathrm{gm}$ ) of Ocimum sanctum L. was extracted with $200 \mathrm{ml}$ volumes of solvents, Ethanol, chloroform and n-butanol, separately at room temperature, in succession about 24 hours. The organic solvent was separated [11].

\section{Preparation of nanoparticles (Table 1):}

Table 1: Formulation it nanoparticles

\begin{tabular}{|c|c|c|c|c|}
\hline \multirow{2}{*}{ S. No. } & \multirow{2}{*}{ Formulation } & \multicolumn{3}{|c|}{ Ingredients } \\
\cline { 3 - 5 } & & Polymer $(\mu \mathrm{g} / \mathrm{ml})$ & Ginger $(\mathrm{mg} / \mathrm{ml})$ & Tulsi $(\mathrm{mg} / \mathrm{ml})$ \\
\hline 1. & F1 & 25 & 4.861 & - \\
\hline 2. & F2 & 25 & - & 4.323 \\
\hline 3. & F3 & 25 & 2.430 & 2.161 \\
\hline 4. & F4 & 35 & 4.861 & - \\
\hline 5. & F5 & 35 & - & 2.323 \\
\hline 6. & F6 & 35 & 4.861 & - \\
\hline 7. & F7 & 45 & - & 4.323 \\
\hline 8. & F8 & 45 & 2.430 & 2.161 \\
\hline 9. & F9 & 45 & & \\
\hline
\end{tabular}

\section{Preparation of Nanoparticles:}

Preparation of polymer solution: $10 \mathrm{mg}$ Chitosan as polymers was dissolved in solvent and make up the volume up to $10 \mathrm{ml}$. Then concentration of $25,35,45 \mu \mathrm{g} / \mathrm{ml}$ were prepared by mixing $1.25,1.75$ and $2.25 \mathrm{ml}$ solution of polysaccharide in distilled water and make up the volume up to $50 \mathrm{ml}$. Drug (Etoricoxib) solution was prepared 2000 $\mu \mathrm{g} / \mathrm{ml}$ by dissolving $20 \mathrm{mg}$ of drug in acetone and make up the volume up to $10 \mathrm{ml}$. Solution of ginger and tulsi extract with concentration of $4.681 \mathrm{mg} / \mathrm{ml}$ and $4.333 \mathrm{mg} / \mathrm{ml}$ respectively, was prepared in acetone. Then the mixture of extract was prepared by dissolving 2.340 $\mathrm{mg} / \mathrm{ml}$ of ginger and $2.116 \mathrm{mg} / \mathrm{ml}$ of tulsi in acetone. For the formulation of Fl, F4 \& F7, $10 \mathrm{ml}$ of polymer solution with concentration of polymer $25,35 \& 45 \mu \mathrm{g} / \mathrm{ml}$ respectively, were taken separately $\&$ mixed with the help of magnetic stirrer maintaining temperature at $37{ }^{\circ} \mathrm{C}$ with a constant stirring. Then $1 \mathrm{ml}$ ginger extract solution of concentration 4.681 $\mathrm{mg} / \mathrm{ml}$ was mixed to the polymer solution drop wise. For the formulation of F2, F5 \& F8, $10 \mathrm{ml}$ polymer solution with concentration 
of polymer $25,35 \& 45 \mu \mathrm{g} / \mathrm{ml}$ was taken and drop wise $1 \mathrm{ml}$ tulsi extract solution of concentration $4.332 \mathrm{mg} / \mathrm{ml}$ was mixed to the polymer solution. For the formulation of F3, F6 \& F9 the $10 \mathrm{ml}$ polymer solution with concentration of polymer $25,35 \& 45 \mu \mathrm{g} / \mathrm{ml}$ was taken and drop wise $1 \mathrm{ml}$ mixture of ginger and tulsi extract solution of concentration 2.340 and $2.116 \mathrm{mg} / \mathrm{ml}$ was mixed to the polymer solution. The temperature was brought down to the room temp. Then, $5 \mathrm{ml}$ solution of etoricoxib concentration of $2000 \mu \mathrm{g} / \mathrm{ml}$ was added to the each solution with continuous stirring and wait till the acetone was completely evaporated.

\section{Characterization of nanoparticles:}

1. Physical appearance: All the prepared batches of nanoparticles were checked for their clarity.

2. Particle size analysis: The particle sizes of the nanoparticles were determined by using zeta analyzer.

\section{Scanning electron microscope} (SEM) analysis: Surface properties of nanoparticles were studied by using SEM images. SEM study was carried out using zeis EVO analyzer at Amity University, Noida.

4. Drug Content: Drug content was used to determine the amount of drug present in nanoparticles. Formulation $(50 \mathrm{mg})$ was taken and mixed with $10 \mathrm{~m} 1$ of phosphate buffer of $\mathrm{pH} 6.8$ which resulted in the concentration of $100 \mu \mathrm{g} / \mathrm{ml}$. Now keep the solution for $24 \mathrm{~h} \&$ after that again shake it. Then filter it to Whatman filter paper. The absorbance is taken in UV spectrophotometer at, $\max 230,278$ and 672 for etoricoxib, GE and TE, respectively. The drug content was calculated by using formula given in equation 1 .

\section{Drug content $=$ Absorbance $x$ Dilution factor.............Equation 1}

\section{RESULT AND DISCUSSION}

The nanoparticles were developed by the antisolvent method. The solution of etoricoxib, GE and TE were prepared in organic solvent which is used as solvent in the formulation of nanoparticles. The solution of Chitosan as polymers was prepared in organic solvents which are used as antisolvent in the preparation of formulations. Hence, the nanoparticles were developed by the mixing of solvent, antisolvent, supersaturation and nucleation. The supersaturation for onecomponent crystals in liquids can be expressed using equation 3 :

$$
\mathrm{S}=\frac{\mathrm{C}_{\circ}}{\mathrm{C}^{\circ}} \ldots \ldots \ldots \ldots \ldots . . . \ldots \text { Equation } 2
$$


Where the $\mathrm{C}$ is the definite concentration of the active pharmaceutical ingredient in the solution $(\mathrm{mol} / \mathrm{L})$ and $\mathrm{C}^{*}$ is the equilibrium solubility ( $\mathrm{mol} / \mathrm{L})$ of an active pharmaceutical ingredient in a mixture of organic solvent and antisolvent $[\mathbf{1 2}, \mathbf{1 3}]$. It has been established that when the degree of supersaturation is high it leads to the higher nucleation rates and results in lower Gibbs free energy [12, 14, 15].

$$
B^{\circ} \alpha \exp \left(\frac{-\Delta G_{C r}}{k T}\right) \ldots . . \ldots \ldots . . . \text { Equation } 3
$$

Where, $B^{\circ}$ is the rate of nucleation, $\mathrm{k}$ is Boltzmann's constant, $\mathrm{T}$ is the absolute temperature and $\mathrm{G}$, is the critical free energy.

According to the theory of classical nucleation, in the absence of foreign particles and surfaces surroundings, the new solid phase is generated and termed as homogenous nucleation. If the nucleation promoted by the existing foreign particles, it is termed as heterogeneous nucleation. Both the nucleation is known as primary nucleation. The secondary nucleation is started through mechanical abrasion or thermodynamically effects of native crystals.

The free energy for the nucleation of homogeneous is expressed by the help of following equation as [16]:

$$
\Delta G_{C r}=\frac{16 \pi \gamma^{3} s l^{v 2}}{3(k T)^{2}(\operatorname{In}(1+S))^{2}} \ldots \ldots \ldots \ldots \text { Equation } 4
$$

Hence, after combining the equation 4 and 5, the homogeneous nucleation rate in the solution can be expressed by using equation 6 : $B^{\circ}=A_{\text {hom }} \exp \left(-\frac{16 \pi \gamma^{3} s l^{v 2}}{3(k T)^{2}(\operatorname{In}(1+S))^{2}}\right) \ldots$ Equation 5 Where $\mathrm{B}^{\circ}$ is the rate of nucleation, $\mathrm{A}_{\text {hom }}$ is the pre-exponential factor. At the solid-liquid interface, $\gamma_{\mathrm{sl}}$ is interfacial tension, .1) is molar volume, and $\mathrm{T}$ is temperature. $\mathrm{A}_{\text {hom }}$ is depending on the attached solute mechanism on growing particle surface, according to the Lindenberg and Mazzotti [17]. The magnitude order of Ahom usually varies from $10^{32}$ to $10^{36}$. The rates of nucleation mainly depend on the interfacial energy $(\gamma)$ and supersaturation seen from above equation [16].

In another research, Vasaya et al prepared etoricoxib nanosuspension with various stabilizers such as poloxamer and PVP for the enhancement of solubility and dissolution rate through high-pressure homogenization for the treatment of acute gouty arthritis. The results found that the solubility and dissolution rate were increased. Hence the bioavailability is also increased [5]. Kesharwani at al developed gel of etoricoxib for the treatment of arthritis. The solid lipid nanoparticles were prepared at low temperature through emulsification and solidification process by using stearic acid and tween 80 . They compared the carbopol 
gel and hydroxyl propyl methyl cellulose (HPMC) gel and found that the carbopol gel was suitable for the treatment and showed good anti-inflammatory activity [20]. Bilthariya et al prepared nanoparticles of Etoricoxib by using bovine serum albumin with folic acid for the activation of macrophages on the folate receptor in the treatment of arthritis. The nanoparticles were prepared by desolvation method and the result showed that these nanoparticles have the potential to increase the therapeutic effect of drug [21].

In the present study, all the prepared batches of nanoparticles were checked for their clarity. All the formulations were found to be clear and transparent. The particle sizes of the nanoparticles were determined by using zeta analyzer. $1 \%$ solution of the formulation was employed for the zeta analyzer. SEM images of nanoparticles are shown in Figure 1. The size of pores was found ranging from $924 \mathrm{~nm}$ (Fl) to $1084 \mathrm{~nm}$ (F9). The drug content for the nanoparticles of etoricoxib varied form $66.8 \pm 0.05 \%$ (F4) to $85.1+0.04$ $\%$ (F9). The content of GE and BE were found in range from $60.3+0.04 \%(F 4)$ to $72.1+0.05 \%$ (F9) and $59.5+0.04 \%(\mathrm{~F} 8)$ to $80.5+0.03 \%$ (F9), respectively. The drug content of the nanoparticles is shown in Table 2, Figure 2.

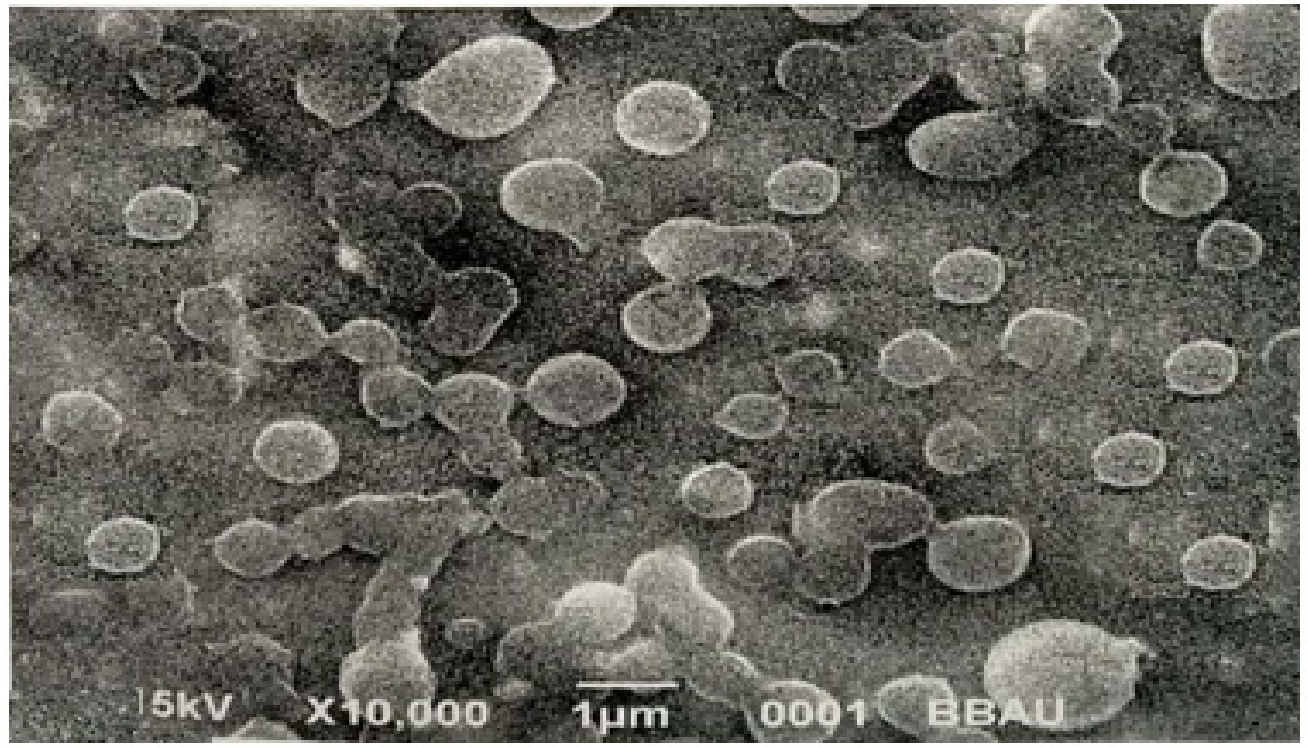

(a) 


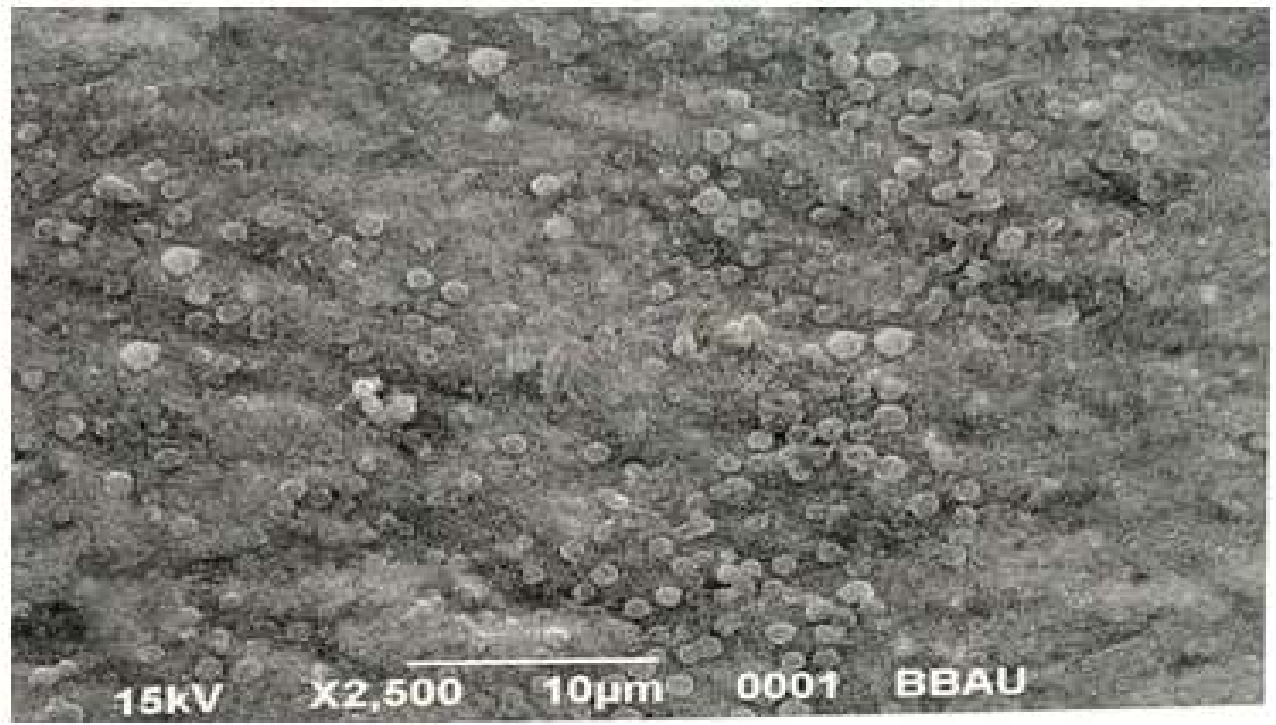

(b)

Figure 1: SEM analysis of Fl (a) X10, 000 (b) X2, 500

Table 2: The drug content of the nanoparticles

\begin{tabular}{|c|c|c|c|c|}
\hline \multicolumn{4}{|c|}{ Drug Content (\%) } & \multirow{2}{*}{$\begin{array}{l}\text { Particle size } \\
\text { (nm) }\end{array}$} \\
\hline Batches & Etoricoxib & GE & TE & \\
\hline F1 & $82.5 \pm 0.02$ & $71.3 \pm 0.01$ & $69.4 \pm 0.05$ & 924 \\
\hline F2 & $68.5 \pm 0.05$ & - & - & 979 \\
\hline F3 & $76.5 \pm 0.01$ & $66.1 \pm 0.05$ & $61.2 \pm 0.05$ & 844 \\
\hline F4 & $66.5 \pm 0.01$ & $61.2 \pm 0.04$ & - & $\mathbf{0 2 3}$ \\
\hline F5 & $74.5 \pm 0.05$ & - & $73.1 \pm 0.05$ & 973 \\
\hline F6 & $75.9 \pm 0.01$ & $62.9 \pm 0.05$ & $71.1 \pm 0.02$ & 1031 \\
\hline F7 & $74.9 \pm 0.01$ & $62.2 \pm 0.05$ & - & 1054 \\
\hline F8 & $82.5 \pm 0.02$ & $71.3 \pm 0.01$ & $69.4 \pm 0.05$ & 985 \\
\hline F9 & $85.6 \pm 0.01$ & $72.9 \pm 0.03$ & $80.9 \pm 0.09$ & 1084 \\
\hline
\end{tabular}

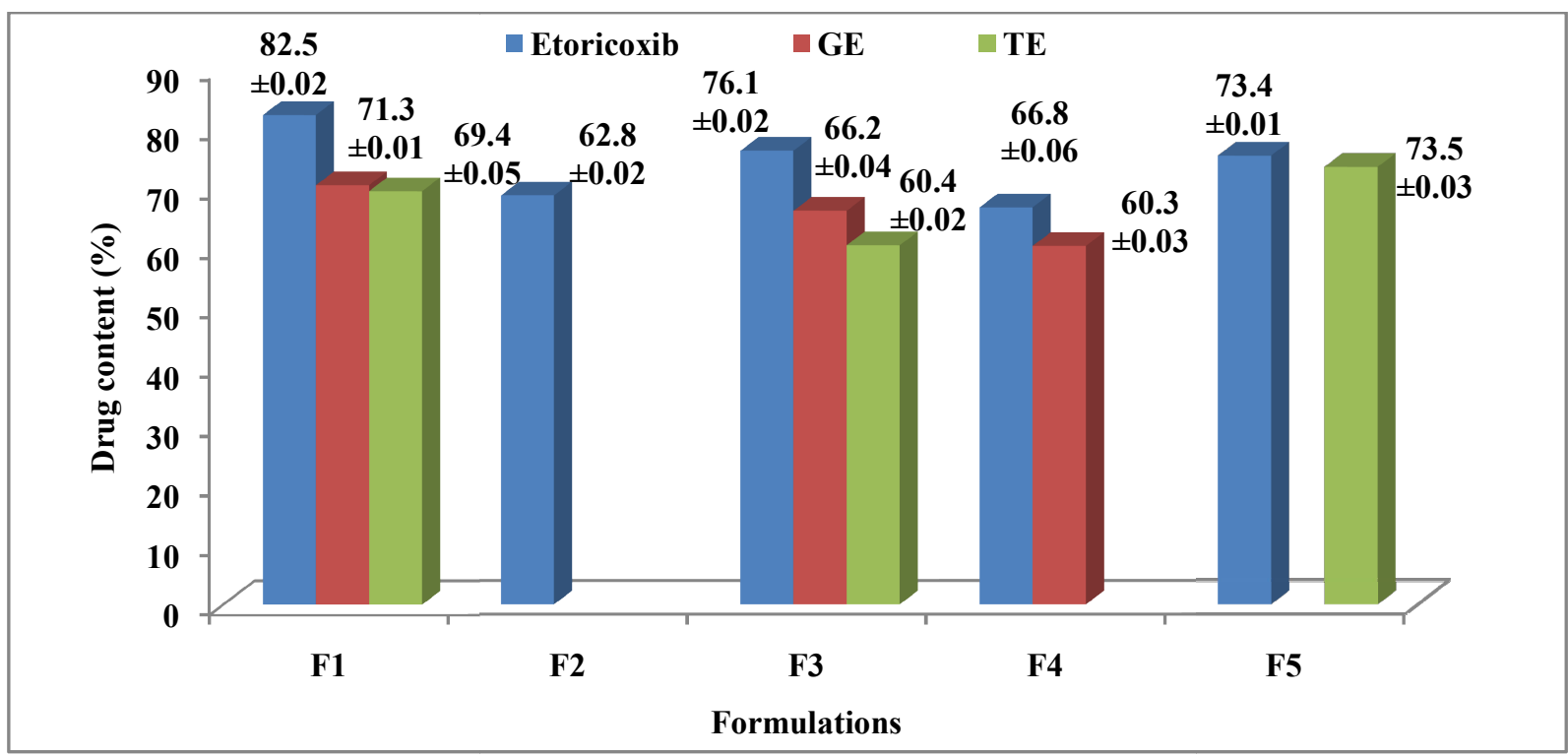

(a) 


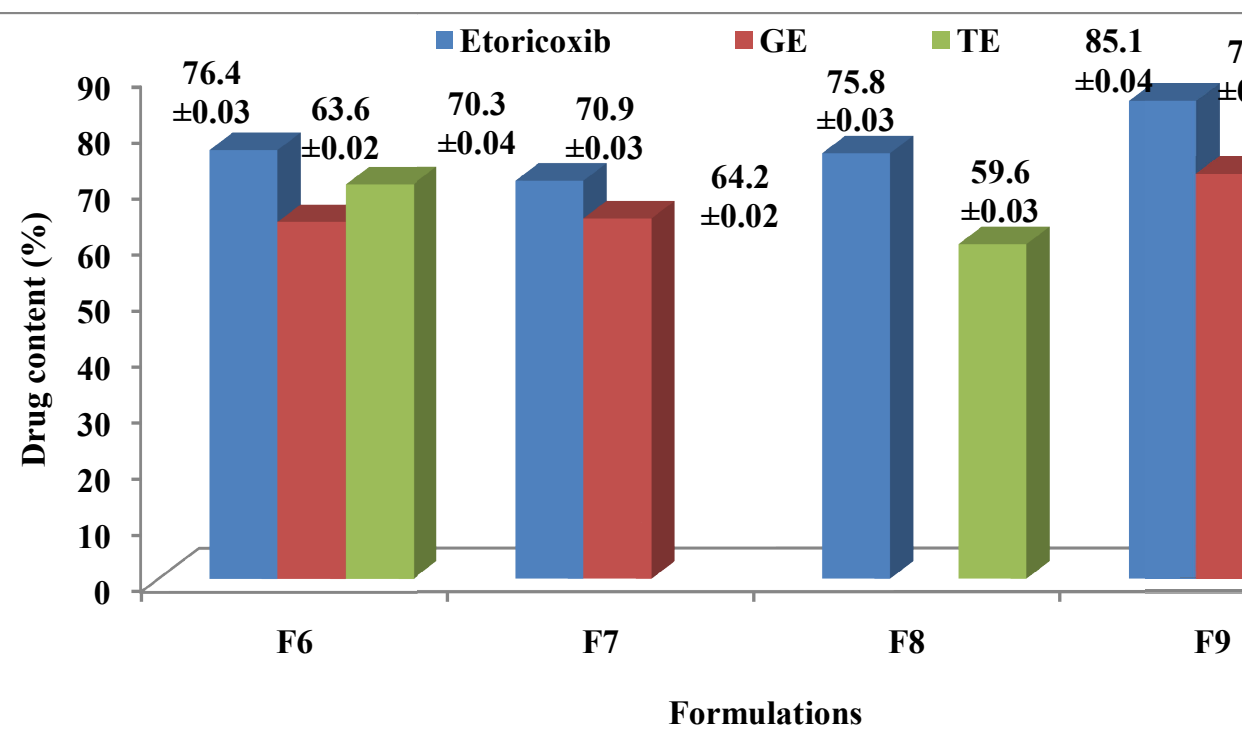

(b)

\section{CONCLUSION}

In this present work, Horicoxib nanoparticles were prepared by using Chitosan as polymers and phytoconstituents such as ethanolic extract of Ginger (Zinger offielnal. Zingiberaceae) root and tulsi (Ocimum sanctum, Lamiaceae) leaves and for enhancing the solubility of drug and bioavailability as well. The prepared nanoparticics was applied treatment of diabetes complications, reduce the pain and inflammation. The extract used in formulation contains antioxidant properties and used against the inflammation of the skin. The results concluded that the nanoparticles were more effective. Formulation reduces the pain without causing adverse effects because it avoids the firstpass metabolism of the drug and the

\section{of the nanoparticles}

formulation is nongreasy in nature. It can be concluded that etoricoxib with phytoconstituents (GE and TE) improved its potential to control the growth of human melanoma cell line (SKMEL-2) in in-vitro conditions.

\section{Acknowledgment}

Authors arc highly thankful to the Mrs. Garima Gupta (Principle) Department of Pharmacy Monad University, Hapur, for providing library and laboratory facilities.

\section{REFERENCE}

[1] Sailaja AK, Begum N. Formulation and evaluation of cox-2 inhibitor (etoricoxib) loaded ethyl cellulose nanoparticles for topical drug delivery. Nano Biomed Eng. 2018; 10(1): 1-9.

[2] Dressman113, Reppas C. In vitro-in vivo correlations for lipophilic, 
poorly water-soluble drugs. Euro J

Pharm Sci. 2000; 11: S73-80.

[3] Alexis F, Rhee JW, Richie JP, Radovic-Moreno AF, Langer R. Farokhzad OC. New frontiers in nanotechnology for cancer treatment. In Urologic Oncology; Seminars and Original Investigations 2008; 26(1): 74-85.

[4] Kocbek P, Baumgartner S. Kristl J. Preparation and evaluation of nanosuspensions fbr enhancing the dissolution of poorly soluble drugs. Int Pharni. 2006; 312(1-2): 179-86.

[5] Vasava SS, Chotai NP, Patel I IK. Formulation and evaluation of nanosuspension drug delivery system of etoricoxib. Pharma Science Monitor. 2015; 6(1): 10-27.

[6] Thorat AA, Dalvi SV. Liquid antisolvent precipitation and stabilization of nanoparticles of poorly water soluble drugs in aqueous suspensions: Recent developments and future perspective. Chem Eng J. 2012; 181: 1-34.

[7] Liu Y, Sun C, Hao Y, Jiang T, Zhong L, Wang S. Mechanism of dissolution enhancement and bioavailability of poorly water soluble celecoxib by preparing stable amorphous nanoparticles. J Pharm Pharm Sci 2010; 13(4): 589-606.

[8] Nile SH, Park SW. Chromatographic analysis, antioxidant, antiinflammatory, and xanthine oxidase inhibitory activities of ginger extracts and its reference compounds. Ind Crops Prod. 2015; 70: 238-44.

[9] Zlotek U, Szychowski KA, Swieca M. Potential in vitro antioxidant, antiinflammatory, antidiabetic, and anticancer effect of arachidonic acidelicited basil leaves. J Funct Foods. 2017; 36: 290-9.

[10] Chitra K, Reena K, Manikandan A, Antony SA. Antibacterial studies and effect of poloxamer on gold nanoparticles by zingiber officinale extracted green synthesis. J Nanosci Nanotechnol. 2015; 15(7): 4984-91.

[11] Sasidharan, S.; Chen, Y.; Saravanan, D.; Sundram, K.M.; Latha, L. Yoga.; Extraction, Isolation And Characterization of Bioactive Compounds From Plants' Extracts: Afr J Tradit Complement Altern Med. 2011, 8(1), 1-10.

[12] Mullin JW, $1 \backslash 11 \mathrm{t}$ J. programmed cooling of batch crystallizers. Chem Eng Sci. 1971; 26(3): 369-77. 
[13] Jones AG, Mullin JW. Programmed cooling crystallization of potassium sulphate solutions. Chem Eng Sci. 1974; 29(1): 105-18.

[14] Dirksen JA, Ring TA. Fundamentals of crystallization: kinetic effects on particle size distributions and morphology. Chem Eng Sci. 1991; 46(10):2389-427.

[15] Sugimoto T. Formation of monodispersed nano-and microparticles controlled in size, shape, and internal structure. Chemical Engineering \& Technology: Industrial Chemistry-Plant Equipment-Process EngineeringBiotechnology. 2003; 26(3): 313-21.

[16] Sohnel 0, Garside J. Precipitation: basic principles and industrial applications. ButterworthHeinemann. 1992.

[17] Lindenberg C, Mazzotti M. Effect of temperature on the nucleation kinetics of a 1-glutamic acid. J Cryst Growth. 2009; 311(4): 1178-84.

[18] Zhang H, Zhai Y, Wang J, Zhai G. New progress and prospects: The application of nanogel in drug delivery. Mater Sci Eng. 2016; 60: 560-8.
[19] Molina M, Asadian-Birjand $M$, Balach J, Bergueiro J, Miceli E, Calderon M. Stimuli-responsive nanogel composites and their application in nanomedicine. Chem Soc Rev. 2015; 44(17): 6161-86.

[20] Kesharwani R, Sachan A, Singh S, Patel D. Formulation and evaluation of solid lipid nanoparticle (SLN) based topical gel of etoricoxib. J App Pharm Sci. 2016; 6(10): 12431.

[21] Bilthariya U, Jain N, Rajoriya V, Jain AK. Folate-conjugated albumin nanoparticles for rheumatoid arthritis-targeted delivery of etoricoxib. Drug Dev Ind Pharm. 2015; 41(1): 95-104. 